\title{
Pilares da Eficácia Administrativa
}

MARIO LOPES

Representante do Diretor-Geral do DASP, no

Estado da Guanabara.

\section{UM TEMA SEMĀNTICO}

$\mathrm{Na}$ lingüística contemporânea, segundo nos informa o acatado semanticista STEPHEN ULLMANN 1, "tornou-se quase axiomático que a completa sinonímia não existe". As palavras eficácia e eficiência, pelo menos em tema de administração, confirmam a asserção do catedrático da Universidade de Leeds. Conquanto, lèxicamente, representem uma abstração com a mesma conotação semântica, quando saem do "estado de dicionário" e entram no contexto sintático, passam a constituir palavras-fato, com conteúdo de sentido bastante diferenciado. Não podem, portanto, em linguagem de administradores, ser permutáveis. E nem por isso se poderão criticar os administradores. Muito menos caberá acusá-los de criar uma linguagem especial. Sabe-se que os grupos profissionais e sociais, ao longo dos seus contatos, criam uma língua peculiar, em que vocábulos gerais assumem significação particularizante e restrita. A palavra exercício, por exemplo, é de uso freqüente e tem significação muito conhecida. Mas, quando usada dentro de grupos profissionais bem definidos, apresenta-se com aspectos semânticos variados e passa a ser entendida diferentemente. Quem quiser comprovar o fato pergunte, sucessiva e particularmente, a um militar, a um estudante ou professor, a um funcionário público, a um técnico de orçamento, a um frade e a um técnico de Educação física, técnico de futebol ou ginasta: "Que há com - exercício?" O militar suporá, de imediato, que se trata de alguma manobra de tropa; o estudante ou professor, de qualquer trabalho escolar; o funcionário público, de assuntos de fre-

1 STEPHEN ULLMANN: Semântica - "Uma Introdução à Ciência do Significado" - Fundação Calouste Gulbenkian - Lisboa, 1967. 
qüência ou prestação de serviços inerentes ao seu cargo; 0 técnico de orçamento, de período durante o qual se faz a arrecadação da receita e se realizam as despesas de um orçamento; o frade, de práticas espirituais e o técnico de educação física, técnico de futebol ou ginasta, de adestramento físico ou de treino de conjunto.

CHESTER I. BARNARD ${ }^{2}$, num livro clássico e ainda hoje de leitura obrigatória, ao que nos parece, foi o primeiro a notar que as palavras eficácia e eficiência exprimiam conceitos distintos. Considerando especificamente a separação entre fins objetivos e fins subjetivos, concluiu aquêle executivo, lùcidamente, que a eficácia se caracteriza pela completa realização dos objetivos da organização, ao passo que a eficiência diz respeito à atuação das pessoas que integram essa organização.

Pode-se acrescentar que a eficácia traduz sempre resultados lucrativos e que a eficiência é a atividade correta, certinha, tècnicamente perfeita, mas que pode não oferecer qualquer resultado proveitoso.

AUREN URIS ${ }^{3}$ salienta o fato de que um administrador pode ser eficaz sem ser eficiente: obter resultados lucrativos à custa de sentimentos feridos, desmoralização e descontentamentos. Uma ilustração conclusiva: o quadro A de futebol, que jogou durante todo o tempo primorosamente e perdeu de 3 a 0 para o quadro $B$, que jogou mal, mas aproveitou bem as oportunidades de marcar tentos, foi eficiente, mas não foi eficaz. O quadro $\mathrm{B}$, ao contrário, não foi eficiente, mas foi eficaz.

Fica entendido, portanto, que neste artigo, quando nos referimos à eficácia administrativa, temos em vista a administração que apresenta resultados vantajosos.

\section{O HOMEM COM QUALIFICAÇÕES ESPECIFICAS}

O eminente economista norte-americano WALT W. ROSTOW ${ }^{4}$ arrola, como tarefa essencial ao processo de desenvolvimento e ao impulso continuado de crescimento, a construção, entre outras, da infra-estrutura da modernização na educação, nos transportes, na energia, na administração.

2 CHESTER I. BARNARD: "The Functions of the Executive" - Harvard University Press - Cambridge, 1950.

3 AUREN URIS: "Novas Técnicas de Direção" - IBRASA - São Paulo - 2a edição, 1964.

4 WALT W. ROSTOW: "View From The Seventh Floor" - Harper \& Row Publishers - New York, 1964. 
Não é possível, portanto, a arrancada inicial para o progresso de países que se esquecem de modernizar a sua administração. Essa modernização supõe mudanças profundas na estrutura dos órgãos e na mentalidade e nos métodos de trabalho daqueles que administram ou são administrados. Trata-se de uma corrida mundial de fôlego, em que todos têm pressa de chegar. E em que chegar atrasado equivale a sucumbir sufocado pelo pó das dificuldades ocorrentes ou levantadas.

No Brasil, os governos pós-Revolução vêm lutando porfiadamente para desmentir as cassandras da futurologia mundial e desmoralizar-Ihes as profecias, extrapolações, conjecturas sistemáticas, e sabemos mais lá o quê! HERMAN KAHN já está revendo suas afirmações... O fato é que na área das comunicações, dos transportes, da energia, da economia, da educação, da administração e outras mais, estamos obtendo êxitos promissores e muito significantes.

Nada obstante, se já obtivemos alguns êxitos, no que respeita à administração, isso não quer dizer que, nesse setor terciário, atingimos o ponto-ótimo. Muito há que fazer e rever ainda. Uma nova ordem de atuação reclama, para comandá-la, não o servidor comum, e sim o servidor que represente o homem com qualificações específicas. Sòmente êsse homem é capaz para cumprir eficazmente a sua tarefa.

Entretanto, o homem com qualificações especificas, o homem com talento e conhecimentos especializados não é fácil de encontrar, sem que se realize uma singela e prévia operação de recrutamento. Ao sair de alguma organização, é logo procurado por outra. Quando não é atraído por uma emprêsa particular, êsse homem, muitas vêzes, emigra para outros países.

Onde, porém, se encontra tal homem? Como encontrá-lo? Esse homem se encontra em quase todos os pontos do território nacional e pode ser detectado de forma simples e impessoal: processos de seleção inicial. Êsse processo tem, todavia, de ser compatível e realístico. Nada de multiplicidade de provas que visam a escolher gênios, mas que acabam por apontar apenas memorizadores a curto prazo.

Em seguida ao processo seletivo inicial, os escolhidos deverão submeter-se a um período de treinamento, em que lhes Serão ministrados os conhecimentos teóricos e práticos exigidos pelo cargo, função ou emprêgo que se quiser prover. No caso de cientistas ou de técnicos de gabarito internacional, admitidos para trabalho imediato, o processo seletivo deveria constar apenas de apreciação de documentos curriculares: títulos e ex- 
periência de alto nível. A mais não se submeterá êsse tipo de mão-de-obra.

Enfocando o tema, observa argutamente ASTÉRIO DARDEAU VIEIRA 5: "As Nações Unidas, por exemplo, recorrem ao exame e comparação do curriculum vitae de cada candidato, só raras vêzes lançando mão do concurso escrito, na forma que nos é familiar. E, reconheçamos, dispõem de um excelente corpo de Servidores Civis Internacionais."

O cientista brasileiro MOISÉS NUSSENZWEIG, por sua vez, em relatório preparado para a reunião de físicos brasileiros em Washington, realizada em setembro de 1967, notava, relativamente à área de recrutamento de cientistas: "Os métodos de preenchimento de cargos por concursos são um fenômeno peculiar quase exclusivamente ao Brasil". E observava mais adiante: "... há vários casos de cientistas, de renome internacional, que no exterior seriam convidados para dirigir laboratórios ou institutos e no Brasil, quando muito, alcançam a posição de instrutores ou assistentes." Essa tradição, tão inútil quanto estranha, no caso de cientistas e técnicos de renome público e notório, tem recebido o tratamento adequado por parte dos responsáveis pela matéria. Isso não mais ocorrerá. O homem de talento, o homem com qualificações especificas, trabalha eficazmente para quem o contrata primeiro e primeiro Ihe garante condições ideais de trabalho. Desenvolvimento é, também, maturidade de ação. Os dirigentes brasileiros já estão cientes e conscientes de que precisamos, como pré-condição para a arrancada que iniciamos em direção ao progresso auto-sustentado, da maior quantidade possível de homens com qualificações específicas. Os países, nos seus três setores clássicos de comparação evolutiva, primário (agricultura e mineração), secundário (indústrias manufatureiras) e terciário (comércio, serviços públicos, educação) necessitam continuamente dêsse tipo de mão-de-obra. E êste tipo de mão-de-obra é, sem dúvida, o principal pilar da eficácia administrativa. Como sàbiamente afirmava BACON: "Saber é poder".

\section{A ORGANIZAÇÃO ADEQUADA}

O progresso tecnológico, para ser alcançado em qualquer dos seus níveis, exige, como pré-requisito, que os homens se movimentem dentro de áreas de trabalho planejado, coordenado e sob contrôle racional. A organização formal, representada pelas clássicas estruturas profundas, em que os niveis hierár-

5 ASTÉRIO DARDEAU VIEIRA: "A Administração de Pessoal Vista pelos Chefes de Serviço" - Fundação Getúlio Vargas - Brasil, 1967. 
quicos se multiplicam e se complicam, muitas vêzes não é eficaz. Os organogramas caprichosamente traçados e lindamente coloridos são de discreta utilidade como ferramenta básica de trabalho. Só quem sente falta dêles, como peça de efeito, são as paredes das repartições, dos escritórios, das oficinas e das fábricas. Organogramas, por si sós, não significam que as unidades que o compõem têm sua carga de trabalho e sua lotação avaliada e bem distribuída. Não mostram como se movimenta o fluxo de serviço, nem deixam que se visualize a rêde de comunicações para o processo decisório. Por isso, quando temos em mãos apenas o organograma de uma entidade, podemos afirmar, com a máxima segurança, que não temos quase nada. Contudo, por incrível que isso possa parecer a qualquer pessoa, o que freqüentemente acontece com a maior parte dos técnicos de organização é uma preocupação obsessiva com a feitura de organogramas. Para êsse grupo de obcecados, quanto mais bonito o organograma e quanto mais arabescado, melhor e mais eficaz será a organização. Êsse obscurecimento da realidade pode causar e tem causado alegria ao técnico que o comete, mas pode ser fatal para as organizações. A ausência de realismo e as idéias preconcebidas configuram o pior inimigo de qualquer empreendimento. Em tema de organização, não há como aceitar generalizações nem palpites, partam de onde partirem. Trata-se de um campo fortemente especulativo, onde teorias não comprovadas resistem a qualquer tentativa de análise sistemática. A organização constitui um elemento indispenSável ao êxito. Precisa, todavia, que tenha assento não nas improvisões de gabinete, por mais eminentes que sejam os improvisadores, mas na observação sistemática daquilo que se quer estruturar. HERBERT SIMON ${ }^{6}$ procedeu a um exame completo e rigoroso da chamada teoria clássica da organização. E inegável que a crítica dêsse eminente mestre do Positivismo Lógico foi extremamente útil.

Mostrou-nos êle que em organização há muitos devaneios e que alguns dos antigos princípios existentes não passam de fantasia ou poesia administrativa. O fato positivo e real, porém, é que nem SIMON nem qualquer outro adepto de sua escola apresentou muita coisa de concreto para ser seguida. A crítica que fizeram pode ser classificada de genial. Todavia, não vai além de crítica desacompanhada de alternativas. Não há, portanto, coisas definitivas nem panacéias em organização. Os administradores devem saber evitar os arremessos patológicos

6 HERBERT SIMON: "Administrative Behavior" - MacMillan Company - New York, 1958. 
e alucinantes dos organizadores que projetam modelos estruturais em salas de aula e bibliotecas e têm a pretensão de que são válidos e fecundos para serem adotados na área da administração pública ou privada. O que o administrador deve procurar é o modo certo de operar, e não o modêlo recomendado por A ou B. E, a fim de se achar o modo operacional correto para uma instituição, tem-se que satisfazer a um elenco de fatôres pré-condicionais, que demandam trabalho sério, árduo e pertinaz, sem compromissos com escolas quaisquer. O verdadeiro administrador somente tem compromissos com a eficácia. Inexistindo êsse compromisso, podemos estar em presença de um capataz, nunca de um administrador.

Assumindo a responsabilidade pela Direção-Geral do DASP, GLAUCO LESSA DE ABREU E SILVA, um dos ases da moderna administração pública brasileira, depois de uma longa e aturada atividade prospectiva e analítica, com a sua equipe de trabalho, propôs que a recomposição estrutural e funcional do importante órgão se fizesse dentro de um esquema nôvo e de promissora operacionalidade. Verificou e comprovou o dinâmico executivo que as estruturas clássicas que alguns autores recomendam, com pouca variação, não se diferençavam muito daquela em que vinha atuando o órgão, sem qualquer eficácia possível. Depois de uma série de análises, a Organização Estruturada em Função de Projetos se impôs, ostensivamente, como a mais adequada.

Dêsse modo, foi introduzida pioneiramente no Brasil, na prática administrativa, a Organização Estruturada em Função de Projetos, que, doravante, identificaremos com a sigla ORPRO.

Trata-se de uma concepção organizacional perfeitamente lógica e altamente eficaz para a concretização de projetos. Não obstante ter-se operado há poucos meses, a modernização do DASP já vem mostrando impressionante rendimento de trabaIho, sendo inúmeros os projetos específicos iniciados e completados. $E$ isso está acontecendo ainda na delicada faixa transicional gerada pelo ajuste estrutura antiga/estrutura nova.

GLAUCO LESSA DE ABREU E SILVA tem identificado na GLAUCO LESSA DE ABREU E SILVA tem identificado
aplicação da ORPRO a seguinte constelação de vantagens
práticas:

I - Adaptabilidade e maneabilidade total.

II - Estrutura plana e cadeia de comando curta.

III - Execução cabal dos objetivos do órgão;

IV - Institucionalização do planejamento e das projeçőes específicas. 
V - Trabalho ininterrupto.

$\mathrm{VI}$ - Redução de custos operacionais.

VII - Emprêgo efetivo e racional da mão-de-obra existente.

VIII - Velocidade máxima nas comunicações.

IX - Trabalho cronogramado.

$X$ - Coesão interpessoal dos Grupos-Tarefa.

$\mathrm{XI}$ - Funcionalidade em ponto-ótimo.

XII - Resultados positivos.

Enumeradas as vantagens de ordem prática, decursivas da adoção da ORPRO, passaremos, em seguida, a explicitar e salientar, brevemente, o que nos tem parecido mais significativo em cada uma delas.

Adaptabilidade e maneabilidade total - Não tendo, rìgidamente, uma composição apoiada em muitos níveis de supervisão, a ORPRO apresenta infinitas possibilidades de adaptação às mudanças. É um tipo de organização conversível e que, por isso mesmo, pode modificar-se, constantemente, no sentido da atualização, sem quaisquer repercussões ou abalos maiores. Propicia aos dirigentes, como subproduto dessa faculdade de adaptação a objetivos novos, uma atuação com a máxima flexibilidade e eficácia.

Estrutura plana e cadeia de comando curta -0 excesso de niveis, nas chamadas estruturas de profundidade, dificulta a gerência de qualquer organização. Em contrapartida, a estrutura plana oferece a máxima facilidade para as comunicações, permite amplo contrôle disciplinar e consagra a simplicidade. Além disso, a ORPRO acaba com os elefantes brancos da administração: as unidades dispensáveis, que consomem os orçamentos e atrapalham os órgãos necessários. O excesso de níveis hierárquicos e as cadeias de comando longas, as mais vêzes, constituem matéria de patologia administrativa e organizacional. Não mais se podem tolerar nos dias atuais, em que todos temos pressa.

Execução cabal dos objetivos do órgão - Institucionalizada em função de projetos vinculados aos objetivos das unidades administrativas, a ORPRO proporciona aos homens que nelas têm a responsabilidade de direção a satisfação de irem cumprindo, uma a uma, as metas relativas àquelas unidades. Se os projetos não aparecem, é porque os órgãos não estão realizando as suas finalidades. A ORPRO favorece uma detecção fácil da ociosidade e promove a sua supressão instantânea. No campo de 
atuação da ORPRO não se permitem desocupados nem atividades contemporizadoras ou paliativas. Ou se trabalha realmente, ou não se tem qualquer vez.

Institucionalização do planejamento e das projeções específicas - Essa é uma das vantagens ostensivas da ORPRO: obriga os dirigentes a planejarem sistemàticamente as tarefas das unidades que dirigem e a controlarem as projeções específicas sob a responsabilidade dos grupos que lhes cabe supervisionar diretamente. Todo e qualquer trabalho fica condicionado a um planejamento prévio e passa a constituir um projeto específico, que, uma vez acionado, tem de completar-se. A ORPRO como que ritualiza o planejamento e a ação.

Com isso, provoca a rejeição dos amadores e dos improvisadores em administração, suprimindo, concomitantemente, 0 trabalho realizado em bases tradicionais ou empíricas. A racionalidade com que deve operar a administração exige instrumentos dêsse tipo.

Trabalho ininterrupto - Conseqüentemente às condições de sua operacionalidade, a ORPRO impõe um fluxo de trabalho contínuo das unidades administrativas, onde os Grupos-tarefa se mantêm em atividade permanente. Os projetos não podem sofrer estagnações e, para a execução dêles, há prazos fatais prefixados.

Redução dos custos operacionais - Eliminando os órgãos ou unidades inúteis, a ORPRO elide, também, os dirigentes ornamentais e o pessoal de infra-estrutura supérfluo. $E$ quando se trabalha com os homens certos para o trabalho certo, dimensionando, com exatidão, executantes e carga de trabalho, os custos operacionais se reduzem a seus verdadeiros niveis. Exemplo frisante dessa afirmativa se encontra examinando a previsão orçamentária para o custeio da antiga estrutura do DASP e para o custeio da atual ${ }^{7}$. E isso - é de notar - foi conseguido com flagrante aumento de eficácia.

Emprêgo efetivo e racional da mão-de-obra existente - OS objetivos das unidades não deixam de ser alcançados pela inexistência, nelas, de pessoal com qualificações específicas para atividades requeridas por certos projetos especiais. A mão-deobra existente nas unidades é aproveitada racionalmente, ou seja, faz o que deve fazer, para fazê-lo da melhor forma e no menor espaço de tempo. Quando o projeto que se tem em vista exige conhecimentos não encontráveis ou encontrados dentro mesmo das unidades, os dirigentes podem recorrer à mão-de-

7 Decreto n. 66.760/970 - Diário Oficial de 24-6-1970. 
obra necessária existente no mercado de trabalho, em qualquer ponto do território nacional. O que não se pode é deixar de fazer o que se deve por falta de pessoal capaz. O homem com qualificações específicas, quando preciso, tem de ser captado esteja onde estiver. Irracional seria protelar ou adiar eternamente um serviço imprescindivel e prioritário por dificuldade ou inexistência local de mão-de-obra. A ORPRO, no caso, facilita as coisas e não justifica tais procedimentos. Não há apelação possivel para a ociosidade.

Velocidade máxima na transmissão de ordens - Não favorecendo nem permitindo o inadequado crescimento vertical da estrutura dos órgãos, com a conseqüente complicação e tumulto das suas relações internas, as ordens dadas pelos homens de cima chegam aos homens de baixo com a maior celeridade. Igualmente, as necessidades e aspirações dos escalões inferiores sobem ràpidamente. Essa instantaneidade comunicacional é, naturalmente, sobremodo benéfica à operacionalidade dos órgãos. Tanto os comandantes quanto os comandados passam a saber, sem ruídos deformadores, o que se quer, como se quer e para quando se quer. E quando as ordens são bem compreendidas, o serviço é bem executado.

Trabalho cronogramado - Se o organograma apresenta apenas um valor relativo, visto como não é mais que um retrato - uma figura parada, imóvel, entenda-se - de uma organização, o cronograma é um excelente e indispensável instrumento de contrôle para os dirigentes e de sinergia para os responsáveis por determinada tarefa. A ORPRO adota o cronograma como ferramenta rotineira de trabalho.

Coesão interpessoal dos Grupos-tarefa - Os integrantes dos Grupos-tarefa, tendo pela frente um trabalho bem definido, cuja entrega tem de ser feita em prazo certo, unem-se firme e solidàriamente para cumprir essa finalidade. A não entrega do Serviço, no prazo prefixado, redundará em desprestígio e dissolução do grupo, além de outras possíveis sanções administrativas. Dessa forma, não ocorrem disputas interpessoais e os componentes do grupo buscam ajudar-se, incessantemente, para que a tarefa que Ihes foi cometida se complete integralmente e com o maior grau de perfectibilidade.

A ORPRO é, portanto, um campo favorecedor da participação e do espírito associativo dos homens que trabalham em tôrno da corporificação de objetivos comuns.

Funcionalidade em ponto-ótimo - A ORPRO não é, evidentemente, como que uma cruz afastando o demônio de tôdas 
as dificuldades que as unidades administrativas de qualquer porte podem apresentar e, mesmo, sempre apresentam. A sua adoção e a sua implantação têm de ser feitas na base de estudos prévios e com as maiores cautelas.

Quando, porém, se configura adequada a um dado tipo de atividade, obtêm-se com ela as maiores satisfações possiveis. Não há - pode-se afirmar com a maior tranqüilidade e segurança -, em organização, estruturas perfeitas nem modelos de encomenda. Como na Farmacologia, em Organização não há panacéias prescritíveis. No entanto, a ORPRO é uma alternativa que está merecendo e vai merecer ainda mais, em futuro próximo, a maior consideração. Tudo está mudando, no mundo, como decorrência dos empolgantes feitos tecnológicos da prodigiosa época em que vivemos. As estruturas organizacionais que conhecemos atualmente também vão mudar fatalmente. Os organogramas existentes terão de ser revistos para se adaptarem à dinâmica de trabalho determinada pela revolução introduzida nas organizações pelos computadores. E a ORPRO representa uma opção consistente e vàlidamente digna de ponderação.

Resultados positivos - Em têrmos de resultados, não há como negar que a ORPRO é um dos mais prometedores terrenos organizacionais. Altos administradores terão de formular estratégias gerais; administradores menores ver-se-ão forçados a apresentar projetos específicos e resultados administrativamente rentáveis. A ORPRO estabelece o trabalho em equipe e vincula-o a um projeto preestabelecido racionalmente e a ser concluído em tempo prefixado. A estrutura propiciada pela ORPRO concilia, nos seus exatos e precisos componentes, os elementos estratégicos e táticos de que tôda administração necessita.

Estendemo-nos, propositadamente, sôbre o nôvo tipo de estrutura organizacional que o administrador GLAUCO LESSA DE ABREU E SILVA inseriu, com espetular êxito, na dinâmica do serviço público federal, porque, no DASP, a sua adoção pode ser considerada um êxito permanente. No entanto, o que o administrador responsável tem que considerar, em cada caso, antes de tudo, é a opção pela organização adequada, indubitàvelmente outro pilar indiscutível da eficácia de uma administração.

\section{O INSTRUMENTO LOGISTICO FUNDAMENTAL}

SERVAN SCHREIBER ${ }^{8}$, em livro de sucesso mundial, afirmou que o notável e famoso engenheiro eletrônico JACQUES

8 JEAN JACQUES SERVAN SCHREIBER: "O Desafio Americano" Editôra Expressão e Cultura - Rio de Janeiro, 1968. 
MAISONROUGE, com tôda a sua responsabilidade de Presidente da IBM World Trade Corporation e de Vice-Presidente da International Business Machines Corporation, garantiu que a indústria dos computadores eletrônicos - também conhecidos como ordenadores e calculadores - seria, entre 1970 e 1980, a terceira grande indústria do mundo, em volume, depois da do petróleo e da do automóvel. E registrou, mais adiante, que JOHN DIEBOLD, outro engenheiro de renome, que criou, independemente, embora ao mesmo tempo, com D. S. HARDER, Vice-Presidente Executivo da Ford Motor Company, de Cleveland, o têrmo automação (automation), chamara atenção para o fato de que "os ordenadores constituirão, a partir de 1970, a mais pesada verba de investimento das emprêsas. No mínimo, $10 \%$ do total de investimentos".

Mas os ordenadores não sòmente estão invadindo as emprêsas industriais. Estão penetrando fulminantemente, também, nos bancos, nas companhias de seguro, nas pesquisas cientificas, nos escritórios, nos centros de estatísticas e nas administrações pública e privada. Nas repartições governamentais, os computadores estão sendo introduzidos de forma física direta, através de compra, ou de forma indireta, através de aluguel da capacidade ociosa de terminais descentralizados das organizações especializadas existentes. Portanto, quem tem numerário suficiente compra e quem o não tem aluga. $O$ que ninguém quer é prescindir dos benefícios que a velocidade dos calculadores imprime aos serviços.

Os homens vivem cercados, em todos os lugares, por uma tremenda massa de informações. Essas informações precisam ser agrupadas, criticadas, selecionadas e processadas, a fim de que delas se extraiam conclusões e, em seguida, se tomem decisões eficazes. Qualquer ser humano, em tais circunstâncias, Se sentirá dilacerado pela mole de trabalho que lhe cumpre realizar, até que possa chegar ao estágio derradeiro, que é a decisão, o julgamento.

Como dispensar o computador? O homem precisa descansar o seu cérebro, que trabalha eletroquimicamente, e dar trabalho ao calculador, que opera eletrônicamente. Agir de outro modo seria transigir com a irracionalidade. Em nome de quê, ha surpreendente era em que vive, deve o homem puxar carga? Seria como que não nos apercebermos de que, queiramos ou não queiramos, estamos todos irremediàvelmente envolvidos Pelo progresso e pelo avanço da tecnologia. 
Espanta-nos, realmente, que um espírito da latitude cultural e cientifica de um NORBERT WIENER ${ }^{\circ}$ delineie, com as tintas da tragédia, êste forte quadro: "Recordemos que a máquina automática, qualquer que seja nosso pensamento acêrca dos sentimentos que possa ou não ter, é o exato equivalente econômico do trabalho escravo. Qualquer mão-de-obra que concorra com o trabalho escravo deve aceitar-lhe as condições econômicas. Está claro que isso suscitará uma situação de desemprêgo, comparada à qual a atual recessão, e mesmo a depressão de trinta, parecerá uma brincadeira".

Quem decerto está com a razão é o lúcido e extraordinário ROBERT S. MCNAMARA ${ }^{10}$, sem confronto possivel, o maior dos administradores aparecidos nos últimos tempos: "Parece, em todo caso, um tanto prematuro preocupar-nos com a idéia de que um computador está a ponto de substituir o cérebro humano. A parte tudo o mais, o próprio cérebro é um fantástico computador, é a minúscula parcela mais grandiosa do Universo. Embora pese sòmente 1.300 gramas, contém cêrca de dez bilhões de células nervosas, cada uma das quais contém, aproximadamente, 25.000 possíveis interligações com as demais. Calculou-se que, para construir um computador suficientemente grande para êsse número de escolhas, seria necessária uma área igual a tôda a superfície da terra. Conforme observou Santo Agostinho, o homem contempla, extasiado, as maravilhas do Universo, esquecendo-se de que êle próprio é a maravilha maior de tôdas."

o computador é que é o servo do homem, e não o seu senhor. Por trás de qualquer computador haverá sempre um homem para alimentá-lo com uma programação. Os especialistas em computação sabem que o ordenador não passa de uma máquina de somar em alta velocidade. $O$ que sai dela depende do que nela entra. Dizem êles, a título de piada, que, "se entrar lixo, sai lixo".

Os que vêem perigos na atividade do computador são os românticos e os fantasistas de tôdas as épocas. Se Ihes dependêssemos das decisões, ainda viveríamos todos em cavernas e cobertos de peles de animais.

O próprio NORBERT WIENER, tão apegado a mitos, confessou que, depois de ter participado de duas grandes reuniőes

9 NORBERT WIENER - Cibernética e Sociedade (O Uso Humano de Sêres Humanos) - Ediçäo Cultrix - São Paulo - 1968. 10 ROBERT S. MCNAMARA: A Essência da Segurança - IBRASA -
São Paulo, 1968 . 
com representantes do mundo empresarial, já não se sentia tão pessimista, pois comprovara que todos os presentes tinham consciência plena de conduzir a nova tecnologia para benefício do Homem, a fim de lhe enriquecer a vida espiritual e proporcionar-Ihe maiores facilidades materiais.

A IBM tem cansado de afirmar que computador não opera sem receber instruções. Como uma criança tem que ser ensinada a atar os cordões dos sapatos, o computador, de igual modo, tem que ser instruído sôbre o que fazer e como fazer.

O Homem não vai ensinar os ordenadores a massacrá-lo, a condená-lo à miséria, ao desemprêgo. Vai utilizá-los, e os tem utilizado, como um auxiliar indispensável, que Ihe evita serviços monótonos e entediantes, que o descansa e, assim, lhe permite viver mais feliz e melhor. Temos, portanto, o computador também como um relevante pilar da eficácia administrativa.

\section{A MANEIRA DE CONCLUSÃo}

Nenhuma administração que se diga responsável pode relegar, como peça subalterna, o homem com qualificações especificas, a organização adequada e o computador. São indiscutíveis pilares da eficácia administrativa. Os que, por inépcia, acomodação ou desatino, não se apoiarem nessas colunas-mestras estarão afastando de si as pré-condições indispensáveis para gerir o êxito. E terão de se contentar com a administração do fracasso. Com todo o merecimento, aliás. 
